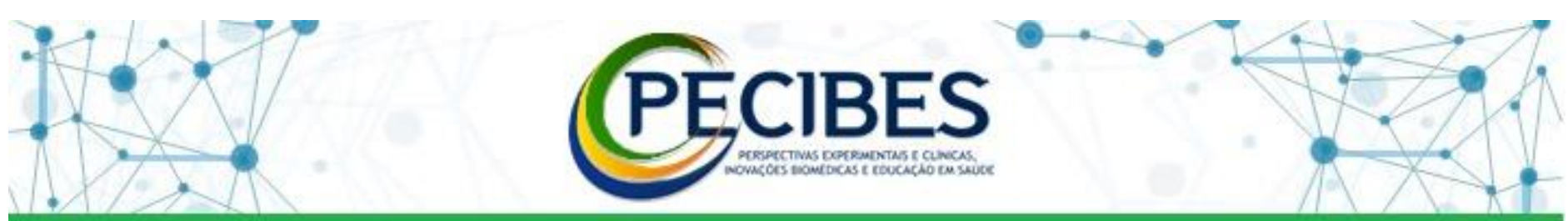

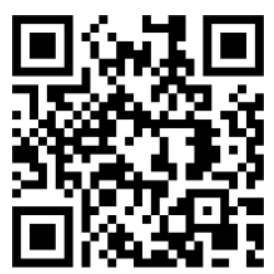

http://www.seer.ufms.br/in dex.php/pecibes/index

*Autor correspondente: Tobias Natan Zuffo, Universidade Federal de Mato Grosso do Sul UFMS. E-mail do autor: tobiasnatan@gmail.com

Descritores:Futebol. Jovens atletas. Incidência de lesões.

Key-words:Young players.Soccer.

\section{Análise da participação de fatores associados e instalação de lesões esportivas no futebol}

Characterization of sports injuries among young soccer players

Tobias Natan Zuffo ${ }^{1}$, Heloyse Elaine Gimenes Nunes ${ }^{2}$, Thayná Escobar Freitas ${ }^{3}$, Mikaela Maria Menezes Silva Queiroz ${ }^{3}$, Paula Felippe Martinez ${ }^{5}$, Cássio Pinho dos Reis ${ }^{6}$, Silvio Assis de Oliveira-Junior ${ }^{5}$

1. Fisioterapeuta, Mestrando no Programa de Pós-Graduação em Ciências do Movimento/ Instituto Integrado de Saúde (INISA), Universidade Federal de Mato Grosso do Sul (UFMS)

2. Profissional de Educação Física, Doutoranda no Programa de Pós-Graduação em Saúde e Desenvolvimento na Região Centro-Oeste (PPGSD), Faculdade de Medicina/UFMS

3. Aluna de graduação, Curso de Fisioterapia, INISA/UFMS

4. Fisioterapeuta, Doutor (a) em Fisiopatologia em Clínica Médica, Docente do INISA/UFMS

5. Estatístico, Doutor em Biometria, Docente do Instituto de Matemática/UFMS

Introdução. Jogadores de futebol estão expostos a variados fatores de risco intrínsecos e extrínsecos para incidência de lesões esportivas (LE). Nesse contexto, a identificação de potenciais fatores associados com a instalação de LE torna-se fundamental, visando-se a proposição de estratégias preventivas no cuidado da saúde de atletas. Objetivo. Analisar a contribuição de diferentes características intrínsecas e extrínsecas na ocorrência de LE em geral, LE em membros inferiores (LMI) e LE traumáticas (LT) no futebol. Métodos. A casuística foi constituída por 176 participantes procedentes do Projeto Escola Pública de Futebol, de Campo Grande, Mato Grosso do Sul (MS). Além de dados demográficos e antropométricos, foram tomadas medidas de pressão arterial, aptidão físico- motora, posicionamento de jogo, histórico e carga horária de treinamento. Para registro de LE, foi utilizado um inquérito de morbidade referida. Os dados foram analisados com emprego de modelos de regressão logística binária e estimativa de odds ratio. O nível de significância foi de 5\%. Estudo aprovado pelo comitê de ética sob O presente estudo foi aprovado pelo Comitê de Ética em Pesquisa (CEP/ UFMS), sob CAAE 79974317.4.0000.0021.. Resultados. Os modelos obtidos para os três desfechos foram estatisticamente significativos (p\&lt;0,05). Circunferência de cintura, histórico e carga horária de treinamento revelaram coeficientes positivos nos três modelos de predição. Pressão arterial diastólica (PAD) também foi diretamente associada com a instalação de LMI, enquanto a amplitude de salto vertical (Potência) mostrou coeficiente positivo para ocorrência de LT. Por sua vez, carga horária mostrou a maior razão de chance para ocorrência de LE em geral $(1,22)$ e LMI $(1,11)$. Conclusão. Entre diversos fatores que podem contribuir para a instalação de LE no futebol, o aumento de 1 hora na $\mathrm{CH}$ semanal de treinamento contribui em $22 \%$ a mais de chance de ocorrência de LE e em $1 \%$ a mais de chance de LMI, enquanto a elevação de $1 \mathrm{~cm}$ na circunferência da cintura contribui em \% a mais de chance de LT. Apoio. UFMS, CAPES, CNPq, FUNDECT. 